\title{
Laryngeal Agenesis
}

National Cancer Institute

\section{Source}

National Cancer Institute. Laryngeal Agenesis. NCI Thesaurus. Code C101279.

A congenital deformity in which there is no laryngeal structure. 